УДК 541.127

\title{
АНТИОКСИДАНТНОЕ ДЕЙСТВИЕ ЭФИРНОГО МАСЛА ТИМЬЯНА ПОЛЗУЧЕГО (THYMUS SERPYLLUM L.)
}

() Л.Р. Варданян ${ }^{1}$, С.А. Айрапетян ${ }^{1}$, Р.Л. Варданян ${ }^{1 *}$, А.Э. Аветисян ${ }^{2}$

${ }^{1}$ Горисский государственный университет, ул. Авангарда, 4, Горис, 3203

(Армения), e-mail: vrazmik@rambler.ru

${ }^{2}$ Арцахский государственный университет, ул. М. Гоша, 5, Степанакерт, 2600 (Нагорно-Карабахская Республика), e-mail: aveartur64@mail.ru

На примере инициированного окисления кумола исследовано антиоксидантное действие эфирного масла тимьяна ползучего. Установлено, что эфирное масло тимьяна ползучего обладает довольно сильным антиоксидантным свойством. Определены содержание антиоксидантов в 1 мг масла $\left(1,43 \cdot 10^{-3}\right.$ моль/л) и температурная зависимость параметров $\mathrm{k}_{7}$ и $\mathrm{k}_{71}$ - характеризующая активность антиоксидантов.

Ключевые слова: тимьян ползучий, Thymus serpyllum L., эфирное масло, антиоксидантная активность.

\section{Введение}

В последние годы наряду с поиском новых лекарственных растений проводится углубленное изучение свойств эфирных масел, традиционно применяемых в медицине парфюмерной и пищевой промышленности. Из эфирных масел лекарственных растений широко используется масло тимьяна ползучего (Thymus serpyllum L.) как лекарственное сырье и пряность в кулинарии.

Эфирное масло тимьяна ползучего (ЭМТ) применяется в традиционной медицине многих стран и народов как ценное лекарственное сырье $[1,2]$. ЭМТ рекомендуется применять как отхаркивающее и болеутоляющее средство при острых и хронических бронхитах, она обладает антимикробной [3], антиоксидантной [4] и спазмалитической [5] активностью. Столь универсальное применение ЭМТ обьясняется содержанием в нем биологически активных веществ. В частности, ЭМТ содержит тимол, карвакрол, бетакариофилен, гамма-терпинен, пара-цимол, пара-цимен, линалоол, камфору, альфа и бетта-пинен, флавоноиды. По результатам работы [6] установлено, что ЭМТ содержит более 55 химических соединений. Причем как процентное содержание отдельных компонентов, так и химический состав масел зависит от экологических и природных условий, а также и географических зон произрастания данного растения [7,8]. Следовательно, изучение химических и отдельных эксплуатационных свойств масел и экстрактов лекарственных растений, растущих в данных зонах, является необходимым условием.

\footnotetext{
Варданян Луиза Размиковна - доцент биохимической кафедры, кандидат химических наук, доцент, e-mail: luisemari@rambler.ru

Айрапетян Сюзанна Арсеновна - преподаватель биохимической кафедры,

e-mail: syuzanhayrapetyan@ rambler.ru

Варданян Размик Левонович - профессор

биохимической кафедры, доктор химических наук, e-mail:vrazmik@rambler.ru

Аветисян Артур Эдуардович - заведующий химической кафедры, кандидат химических наук, доцент, e-mail: aveartur64@mail.ru
}

В настоящей работе нами изучены антиоксидантные свойства ЭМТ ползучего, произрастающего в окрестностях Степанакерта Нагорно-Карабахской республики на высоте 850 м над уровнем моря.

\section{Экспериментальная часть}

Отбор образцов тимьяна ползучего провели в середине июля 2009 и 2012 гг. в период полного цветения. Подготовку сырья (высушивание до воздушносухого состояния), отбор проб и получение эфирного

\footnotetext{
* Автор, с которым следует вести переписку.
} 
масла производили с использованием общепринятых методов [9]. В состав проб входили стебли молодых побегов (25\% от массы собранного сырья), листья и соцветия (20 и 40\% соответственно). Одревесневшие части растений (15\%) удаляли. Эфирное масло получили водяно-паровым методом из высушенного сырья. Навеску сырья массой 100 г погружали в колбу емкостью 1 л, заливали водой $(0,5$ л) и доводили до кипения. Длительность отгонки составляла 3 ч. Внешний вид полученного ЭМТ - прозрачная, светло-желтого цвета жидкость, плотность - 0,928 г/мл, показатель преломления - 1,4975. В работе были использованы два образца ЭМТ, соответственно, полученные в 2009 (ЭМТ-09) и 2012 (ЭМТ-12) гг. Антиоксидантную активность и содержание антиоксидантов-ингибиторов цепных процессов определяли на модельной реакции инициированного азо-ди-изобуторинитрилом (АИБН) окисления кумола, в интервале температур 333-348 К. Отыты по окислению кумола проводили на газометрической установке с автоматическим регулированием давления. Концентрация кумола во всех опытах составляла 2,87 моль/л, обьем реакционной смеси 5 мл. Растворителем реакционной смеси служил хлорбензол. Кумол и хлорбензол после многократного встряхивания с концентрированной серной кислотой промывали дистиллированной водой, сушили над хлористым кальцием и перегоняли при атмосферном давлении. АИБН очищали пятикратным переосаждением из этанола и высушиванием под вакуумом при комнатной температуре до постоянного веса.

Скорость окисления определяли из кинетических кривых поглощения кислорода с использованием уравнения 1.

$$
V=\frac{\Delta \mathrm{O}_{2}}{\Delta t} \cdot \frac{2,65 \cdot 10^{-4}}{T},
$$

где $2,65 \cdot 10^{-4}$ - постоянная газометрической установки; Т - температура бюретки (комнатная температура).

\section{Обсуждение результатов}

На рисунках 1 и 2 представлены кинетические кривые поглощения кислорода окисляющегося кумола в отсутствие (1) и в присутствие ЭМТ-12 и ЭМТ-09 (кривые 2 и 3). Из рисунков следует, что в присутствии ЭМТ поглощение кислорода при инициированном окислении кумола осуществляется с явно выраженными периодами индукции, что свидетельствует о содержании антиоксидантных веществ в его составе. Суммарное содержание антиоксидантов определяли с использованием уравнения 2:

$$
\tau=\frac{f[\operatorname{InH}]}{V_{i}}=\alpha \frac{m}{V_{i}},
$$

где $\tau$ - период индукции, $f$ - стехиометрический коэффициент ингибирования (число радикалов обрывающихся на одной молекуле ингибитора) [ InH] - суммарное содержание антиоксидантных веществ в исследуемом образце ЭМТ, $V_{i}$ - скорость инициирования, m- масса использованного ЭМТ в мг. Опыты показали, что обнаруженные периоды индукции описываются уравнением (2). Результаты расчетов экспериментальных данных приведены в таблице 1. Из таблицы следует, что содержание антиоксидантных веществ в 1 мг масла ЭМТ-12 составляет $(1,418 \pm 0,048) \cdot 10^{-3}$ моль/л, а в ЭМТ-09 - 1,54 $10^{-5}$ моль/л.

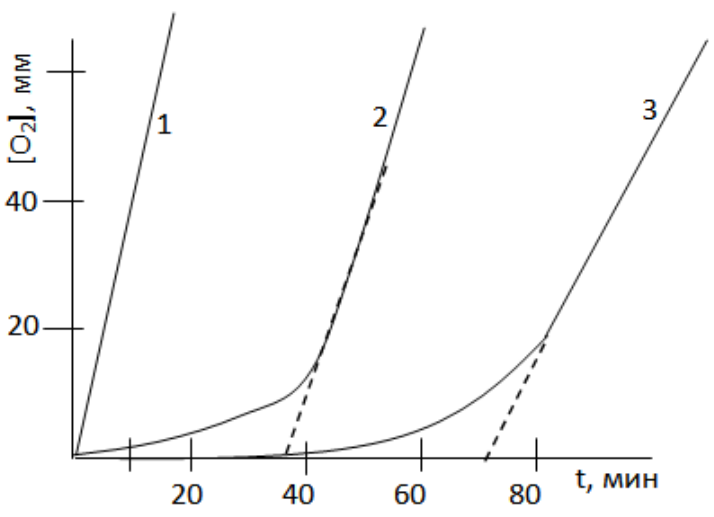

Рис. 1. Кинетические кривые поглощения кислорода окисляющегося кумола в отсутствие (1) и в присутствии 0,19 мг (2) и 0,38 мг (3) ЭМТ12. $\mathrm{V}_{\mathrm{i}}=1,25 \cdot 10^{-7}$ моль $/$ л $\cdot \mathrm{c}, \mathrm{T}=348 \mathrm{~K}$

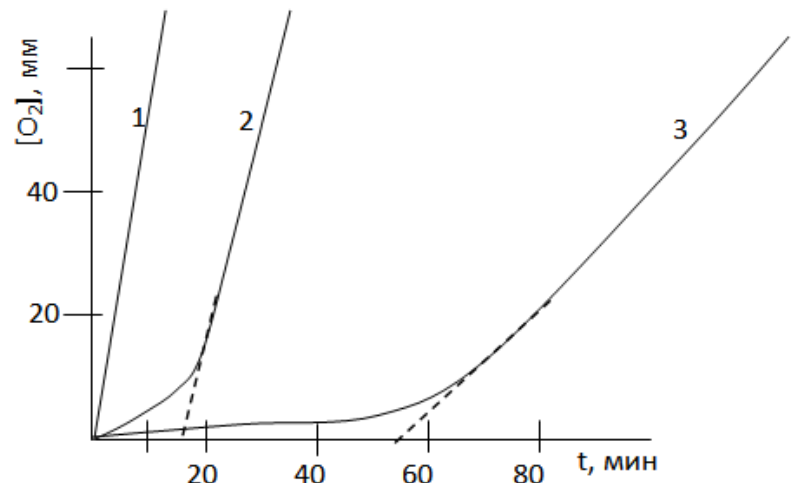

Рис. 2. Кинетические кривые поглощения кислорода окисляющегося кумола в отсутствие (1) и в присутствии 6,44 мг (2) и 27,5 мг (3) ЭМТ-09. $\mathrm{V}_{\mathrm{i}}=1,39 \cdot 10^{-7}$ моль/л $\mathrm{c}, \mathrm{T}=348 \mathrm{~K}$ 
Таблица 1. Содержание антиоксидантных веществ в ЭМТ, Т=348К

\begin{tabular}{|c|c|c|c|c|c|}
\hline \multicolumn{2}{|c|}{$\begin{array}{c}\text { Навеска ЭМТ в реакционной } \\
\text { смеси, мг }\end{array}$} & \multirow[t]{2}{*}{$\tau$, мин } & \multirow{2}{*}{$\begin{array}{c}\text { Содержание антиокси- } \\
\text { дантных веществ, } \\
\text { f [InH] } 10^{4}, \text { моль/л }\end{array}$} & \multirow[t]{2}{*}{$\mathrm{V}_{\mathrm{i}} 10^{7}$, моль/лс } & \multirow{2}{*}{$\begin{array}{c}\text { Содержание InH в одном } \\
\text { мг экстракте } \\
\text { f [InH] } 10^{4}, \text { моль/л }\end{array}$} \\
\hline ЭМТ-09 & ЭМТ-12 & & & & \\
\hline 6,44 & - & 12 & 1,00 & 1,39 & 0,155 \\
\hline 12,75 & - & 24 & 2,00 & 1,39 & 0,157 \\
\hline 27,50 & - & 50 & 4,17 & 1,39 & 0,152 \\
\hline 38,68 & - & 70 & 5,84 & 1,85 & 0,151 \\
\hline- & 0,1 & 19 & 1,43 & 1,25 & 14,30 \\
\hline- & 0,19 & 35 & 2,63 & 1,25 & 13,82 \\
\hline- & 0,38 & 73 & 5,48 & 1,25 & 14,42 \\
\hline- & 0,19 & 71 & 2,66 & 0,625 & 14,02 \\
\hline- & 0,19 & 18 & 2,70 & 2,50 & 14,21 \\
\hline
\end{tabular}

Эти данные свидетельствуют, что за три года содержание антиоксидантных веществ при хранении ЭМТ при комнатной температуре уменьшается примерно в 100 раз $\left(1,418 \cdot 10^{-3} / 1,5410^{-5}=92\right)$. Следовательно, с целью увеличения гарантийного срока и сохранения эксплуатационных свойств ЭМТ необходимо его хранить при минусовых температурах.

При оценке антиоксидантных способностей экстрактов и масел растительного сырья, кроме определения количественного содержания в них антиоксидантных веществ, важным является и установление их антиоксидантных активностей, т.е. определение константы скоростей реакции ингибиторов со свободными пероксидными радикалами $\left(\mathrm{k}_{7}\right)$. Для этого величину $\mathrm{k}_{7}$ определяли по количеству поглощенного кислорода во время периода индукции с использованием уравнения 3 [10].

$$
\frac{\left[\mathrm{O}_{2}\right]}{[\mathrm{RH}]}=-\frac{k_{2}}{k_{7}} \ln \left(1-\frac{t}{\tau_{1}}\right),
$$

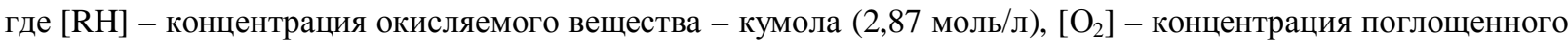
кислорода за время $\mathrm{t}<\tau_{1}, \tau_{1}-$ период индукции, который немного отличается от $\tau$, приведенной в уравнении (2) и в таблице 1 и определяется графически на кинетических кривых поглощения кислорода по координате точки пересечения двух прямых, для которых тангенсы углов наклона связаны соотношением tg $\alpha_{1}$ $=2 \operatorname{tg} \alpha_{2}[10]$ или $V_{\mathrm{O}_{2}}^{\prime}=2 V_{\mathrm{O}_{2}}^{\prime}$, где $V_{\mathrm{O}_{2}}^{\prime}-$ скорость поглощения кислорода после выхода из периодов индукции, $V_{\mathrm{O}_{2}}^{\prime}$ - в присутствии ингибитора (см. рис. 1 , кривая 3 ), $\mathrm{k}_{2}$ и $\mathrm{k}_{7}$, соответственно, константы скоростей реакций продолжения

$$
\mathrm{RO}_{2}^{\bullet}+\mathrm{RH} \stackrel{k_{2}}{\longrightarrow} \mathrm{ROOH}+\mathrm{R}^{\bullet}
$$

и обрыва цепей

$$
\mathrm{RO}_{2}^{\bullet}+\mathrm{InH} \stackrel{k_{7}}{\longrightarrow} \mathrm{ROOH}+\mathrm{In}^{\bullet}
$$

Значения $\mathrm{k}_{2} / \mathrm{k}_{7}$ определяли графически, спрямляя экспериментальные данные в координатах уравнения (3). Откуда, учитывая, что для кумола $\mathrm{k}_{2}=4,677 \cdot 10^{6} \cdot \exp (-9800 / \mathrm{RT})[11]$ вычисляли абсолютные значения $\mathrm{k}_{7}$ в интервале температур 333-348 К. Результаты расчетов приведены в таблице 2. Установлено, что k для исследованных ЭМТ в аррениусовых координатах описывается выражением

$$
\begin{aligned}
\left(\mathrm{k}_{7}\right)_{\text {эмт-12 }}=5,87 \cdot 10^{13} \cdot \exp [-(14500 \pm 250) / \mathrm{RT}], & \text { л/моль } \mathrm{c} ; \\
\left(\mathrm{k}_{7}\right)_{\text {эмт-09 }}=2,77 \cdot 10^{12 \cdot} \exp [-(12100 \pm 200) / \mathrm{RT}], & \text { л/моль } \mathrm{c} .
\end{aligned}
$$

Из кинетических кривых поглощения кислорода (рис. 1 и 2) следует, что скорость окисления кумола после выхода из периодов индукции, в присутствии исследованных масел, остается существенно занижен- 
ной по сравнению со скоростью окисления индивидуального кумола (сравни тангенсы углов прямых 1, 2 и 3). Обнаруженные предельные скорости окисления описываются уравнением (4) [12] (см. рис. 4).

$$
\frac{V_{0}}{V_{\infty}}-\frac{V_{\infty}}{V_{0}}=\frac{k_{7_{1}} f[Q]}{\sqrt{k_{6} V_{i}}}
$$

где $\mathrm{V}_{\mathrm{o}}$ и $\mathrm{V}_{\infty}$ - предельные скорости окисления кумола, соответственно, в отсутствие и в присутствии масел тимьяна, $\mathrm{k}_{71}$ и $\mathrm{k}_{6}$ - константы скоростей реакции линейного

$$
R O_{2}^{\bullet}+Q \rightarrow R O O H+Q^{\bullet}
$$

и квадратичного

$$
R O_{2}^{\bullet}+R O_{2}^{\bullet} \rightarrow \text { молекулярные продукты }
$$

обрыва цепей, [Q] - концентрация продуктов превращения исходных антиоксидантов, содержащихся в исследованных маслах. В расчетах предполагалось [13], что Q образуется по реакции

$$
R \mathrm{O}_{2}^{\bullet}+\mathrm{In}^{\bullet} \rightarrow Q+\text { молекулярные продукты }
$$

и что $[\mathrm{Q}]=[\mathrm{InH}]$.

Из рисунка 4 видно, что предельные скорости окисления кумола в присутствии исследованных масел описываются уравнением (4). Пользуясь уравнением (4) и рисунком 4 определили отношение $\mathrm{k}_{71} / \mathrm{v}_{6}$. Откуда, учитывая, что для кумола $\mathrm{k}_{6}=4,74 \cdot 10^{5} \exp \left(-9800 / \mathrm{RT}\right.$ ] [11] определили значения $\mathrm{k}_{71}$ в интервале температур 333-348 К. Результаты расчетов приведены в табл.2. Спрямляя расчетные данные в координатах $\operatorname{lgk}_{71}-\mathrm{T}^{-1}$ определили температурную зависимость для $\mathrm{k}_{71}$ в аррениусовых координатах, которые выражаются уравнениями:

$$
\begin{aligned}
& \left(\mathrm{k}_{71}\right)_{\text {эмт-09 }}=2,24 \cdot 10^{11} \cdot \exp [-(13400 \pm 250) / \mathrm{RT}], \text { л/мольс } ; \\
& \left(\mathrm{k}_{71}\right)_{\text {эмт-12 }}=9,92 \cdot 10^{9} \cdot \exp [-(12500 \pm 250) / \mathrm{RT}], \text { л/мольс } .
\end{aligned}
$$

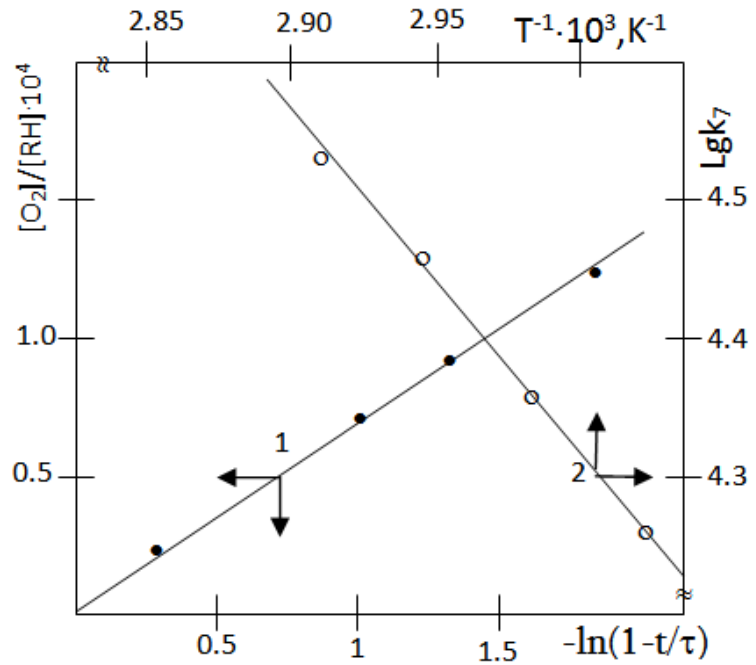

Рис. 3.1 - зависимость концентрации поглощенного кислорода от параметра $-\ln (1-\mathrm{t} / \tau)$, $\mathrm{T}=348 \mathrm{~K} ; 2$ - температурная зависимость константы скорости реакции $\mathrm{k}_{7}$

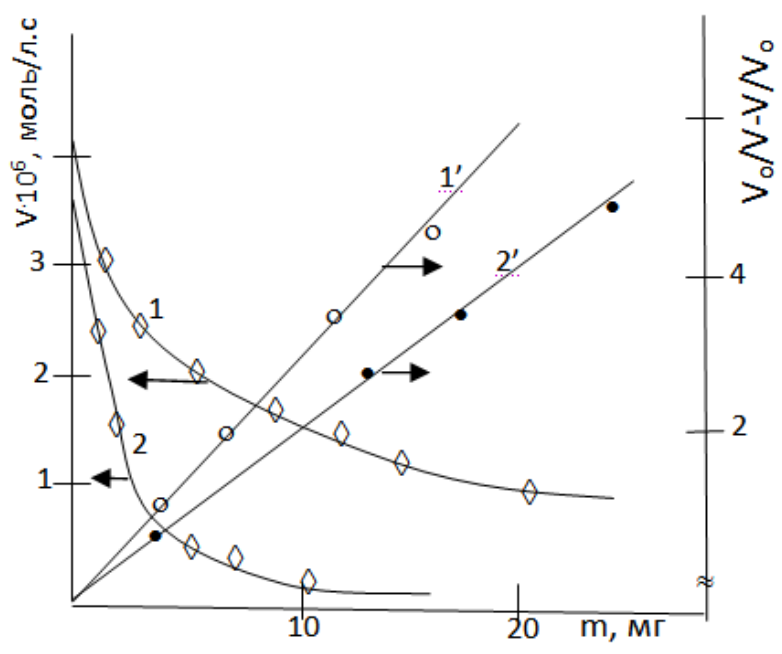

Рис. 4. Зависимость предельной скорости окисления кумола от содержания ЭМТ-09 $\left(1,1^{\prime}\right)$ и ЭМТ-12 (2, 2'). $\mathrm{V}_{\mathrm{i}}=1,25 \cdot 10^{-7}$ моль/л'с, Т=348K 
Таблица 2. Кинетические параметры, характеризующие антиоксидантные активности ЭМТ

\begin{tabular}{|c|c|c|c|c|c|c|c|c|c|}
\hline \multirow[t]{2}{*}{$\mathrm{T},{ }^{\circ} \mathrm{K}$} & \multicolumn{2}{|c|}{$\begin{array}{c}\text { Содержание масла в } \\
\text { кумоле, мг }\end{array}$} & \multirow{2}{*}{$\begin{array}{c}\mathrm{V}_{\mathrm{i}} \cdot 10^{7} \\
\text { моль/лс }\end{array}$} & \multicolumn{2}{|c|}{$\mathrm{V}_{\infty} \cdot 10^{6}$, моль/лсс } & \multicolumn{2}{|c|}{$\mathrm{k}_{7} \cdot 10^{-4}$, л/моль $\mathrm{c}$} & \multicolumn{2}{|c|}{$\mathrm{k}_{71} \cdot 10^{-2}$, л/мольс } \\
\hline & ЭМТ-09 & ЭМТ-12 & & ЭМТ-09 & ЭМТ-12 & ЭМТ-09 & ЭМТ-12 & ЭМТ-09 & ЭМТ-12 \\
\hline 348 & 6,44 & - & 1,38 & 2,50 & - & 6,50 & - & 9,45 & - \\
\hline 348 & 12,88 & - & 1,38 & 1,18 & & 6,98 & - & 9,33 & - \\
\hline 348 & 19,32 & - & 1,38 & 0,82 & & 6,72 & - & 9,51 & - \\
\hline 348 & 27,50 & - & 1,38 & 0,73 & - & 6,66 & - & 8,50 & - \\
\hline 348 & - & 0,19 & 1,25 & - & 2,59 & - & 6,67 & - & 1,58 \\
\hline 348 & - & 0,38 & 1,25 & - & 1,04 & - & 4,56 & - & 1,23 \\
\hline 348 & - & 1,0 & 1,25 & - & & - & 4,48 & - & 1,48 \\
\hline 348 & - & 10,0 & 1,25 & - & 0,12 & - & 4,62 & - & 1,41 \\
\hline 343 & 6,44 & - & 0,66 & 1,05 & - & 5,41 & - & 6,51 & - \\
\hline 343 & - & 0,19 & 0,66 & - & 1,58 & - & 3,40 & - & 1,08 \\
\hline 338 & 6,44 & - & 1,03 & 1,26 & - & 4,16 & - & 4,87 & - \\
\hline 338 & - & 0,15 & 1,03 & - & 1,69 & - & 2,48 & - & 0,82 \\
\hline 333 & 3,22 & - & 0,52 & 0,79 & - & 3,00 & - & 3,82 & \\
\hline 333 & - & 0,10 & 0,52 & - & 0,91 & - & 1,79 & - & 0,62 \\
\hline
\end{tabular}

\section{Сиисок литературы}

1. Гринкевич Н.И., Ладыгина Е.А. Фармакогнозия: Атлас. М., 1989. 512 с.

2. Растительные ресурсы СССР: Цветковые растения, их химический состав, использование. Семейства Hippuridacea - Lobeliaceae. СПб., 1991. С. 100-109.

3. Ismaili H., Sosa S., Brkic D., Fkih-Tetouani S., Ilidrissi A., Touati D., Aquino R.P., Tubaro A. Topical antiinflammatory activity of extracts and compounds from Thymus broussonettii // J. Pharmacy Pharmacology. 2002. Vol. 54, N8. Pp. 137-140.

4. Sokmen A., Gulluce M., Akpulat H.A., Daferera D., Tepe B., Polissiou M., Sokmen M., Sahin F. The in vitro antimicrobial and antioxidant activities of the essential oils and methanol extracts of endemic Thymus spathulifolius // Food Control. 2004. N15. Pp. 627-634.

5. Szentandrassy N., Szentesi P., Magyar J., Nanasi P.P., Csernoch L. Effect of thymol on kinetic properties of Ca and K currents in rat skeletal muscle // BMC Pharmacology. 2003. N3. Pp. 9.

6. Алексеева Л.И., Груздев И.В., Быструшкин А.Г., Тетерюк Л.В. Химический состав эфирного масла эндемичных тимьянов европейского северо-востока России и Урала // Вестник Института биологии. 2011. №10-11. C. 9-14.

7. Корсакова С.П., Работягов В.Д., Виноградов Б.А. Модель эколого-генетического контроля биосинтеза тимола в эфирном масле Thymus L. // Черноморский ботанический журнал. 2006. T. 2, №1. С. 50.

8. Касумов Ф.Ю. фитоценотическая роль некоторых видов рода Thymus L. в сложении растительного покрова Кавказа // Бюллетень Ботанического сада - института ДВО РАН. 2008. Вып. 2. С. 34-40.

9. Государственная фармакопея СССР. Вып. 2. Общие методы анализа. Лекарственное растительное сырье. 11-е изд. 1987. $386 \mathrm{c.}$

10. Цепалов В.Ф., Харитонова А.А., Гладышев Г.Л., Эмануэль Н.М. Определение констант скорости и коэффициентов ингибирования фенолов - антиоксидантов с помощью модельной цепной реакции // Кинетика и катализ. 1977. Т. 18, №5. С. 1261-1266.

11. Денисов Е.Т. Константы скорости гомолитических жидкофазных реакций. М., 1971. С. 51.

12. Денисов Е.Т., Азатян В.В. Ингибирование цепных реакций. Черноголовка, 1997. С. 51.

13. Варданян Р.Л., Варданян Л.Р., Атабекян Л.В. Антиоксидантное действие экстрактов омелы белой, произрастающей на различных деревьях // Химический журнал Армении. 2011. Т. 64, №3. С. 335-340.

Поступило в редакцию 7 сентября 20122. 
Vardanyan L.R. ${ }^{l}$, Hayrapetyan S.A. ${ }^{l}$, Vardanyan R.L. ${ }^{1 *}$, Avetisyan A.E. ${ }^{2}$ THE ANTIOXIDATING ACTIONS OF ETHEREOUS OIL OF THE THYMUS SERPYLLUM L.

${ }^{I}$ Goris State University, ul. Avangarda, 4, Goris, 3203 (Armenia), e-mail: vrazmik@ rambler.ru

${ }^{2}$ Artsakh State University, ul. M. Gosha, 5, Stepanakert, 2600 (Nagorno-Karabakh Republic),

e-mail: aveartur64@mail.ru

On an example initiating oxidation of cumen is investigated the antioxidanting action of the ethereous oil of the Thymus Serpyllum L. It is proved, that the ethereous oil of the greeping thymes possesses quite strong antioxidanting property. The contents of antioxidants are defined in one oils gramm $\left(1,43 \cdot 10^{-3} \mathrm{~mol} / \mathrm{l} \cdot \mathrm{mg}\right)$ and temperature dependance of parameters $\mathrm{k}_{7}$ and $\mathrm{k}_{71}$ characterizing the activity of the antioxidents.

Keywords: Thymus serpyllum L., ethereous oil, activity of the antioxidents

\section{References}

1. Grinkevich N.I., Ladygina E.A. Farmakognoziia. Atlas. [Pharmacognosy. Atlas.]. Moscow, 1989, 512 p. (in Russ.).

2. Rastitel'nye resursy SSSR: Tsvetkovye rasteniia, ikh khimicheskii sostav, ispol'zovanie. Semeistva Hippuridacea - Lobeliaceae. [Plant Resources of the USSR: Flowering plants, their chemical composition and utilization. Family of Islands Hippuridacea - Lobeliaceae.].St. Petersburg, 1991, pp. 100-109. (in Russ.).

3. Ismaili H., Sosa S., Brkic D., Fkih-Tetouani S., Ilidrissi A., Touati D., Aquino R.P., Tubaro A. J. Pharmacy Pharmacology, 2002, vol. 54, no. 8, pp. 137-140.

4. Sokmen A., Gulluce M., Akpulat H.A., Daferera D., Tepe B., Polissiou M., Sokmen M., Sahin F. Food Control, 2004, no. 15, pp. 627-634.

5. Szentandrassy N., Szentesi P., Magyar J., Nanasi P.P., Csernoch L. BMC Pharmacology, 2003, no. 3, pp. 9.

6. Alekseeva L.I., Gruzdev I.V, Bystrushkin A.G., Teteriuk L.V. Vestnik Instituta biologii, 2011, no. 10-11, pp. 9-14. (in Russ.).

7. Korsakova S.P., Rabotiagov V.D., Vinogradov B.A. Chernomorskii botanicheskii zhurnal. 2006, vol. 2, no. 1, pp. 50. (in Russ.).

8. Kasumov F.Iu. Biulleten' Botanicheskogo sada - instituta DVO RAN, 2008, no. 2, pp. 34-40. (in Russ.).

9. Gosudarstvennaia farmakopeia SSSR. Vyp. 2. Obshchie metody analiza. Lekarstvennoe rastitel'noe syr'e. 11-e izd. [State Pharmacopoeia of the USSR. Part. 2. Common methods of analysis. Herbal drugs. 11th ed.]. 1987, 386 p. (in Russ.).

10. Tsepalov V.F., Kharitonova A.A., Gladyshev G.L., Emanuel' N.M. Kinetika i kataliz, 1977, vol. 18, no. 5, pp. $1261-1266$. (in Russ.).

11. Denisov E.T. Konstanty skorosti gomoliticheskikh zhidkofaznykh reaktsii. [The rate constants of homolytic liquidphase reactions]. Moscow, 1971, p. 51. (in Russ.).

12. Denisov E.T., Azatian V.V. Ingibirovanie tsepnykh reaktsii. [Inhibition chain reactions]. Chernogolovka, 1997, pp. 51. (in Russ.).

13. Vardanian R.L., Vardanian L.R., Atabekian L.V. Khimicheskii zhurnal Armenii, 2011, vol. 64, no. 3, pp. $335-340$. (in Russ.).

Received September 7, 2012

Revised December 7, 2012

\footnotetext{
* Corresponding author.
} 